\title{
Vegetacion atrial gigante complicada con abscesos pulmonares multiples
}

Dra. Cyntia Zulema Machain Leyva

Instituto Mexicano del Seguro Social, Mexico

Recibido: 20/09/2021

Aceptado: 10/10/2021

En línea: 15/12/2021

Citar como: Machain Leyva C.:Vegetación atrial gigante complicada con abcesos pulmonares múltiples. RETIC. 2021 (Diciembre); 4 (3): 44-46. doi: 10.37615/retic. v4n3a12

Cite this as: Machain Leyva C.: Gaint atrial vegetation complicated with multiple pulmonary abceses. RETIC. 2021 (December); 4 (3): 44-46. doi: 10.37615/retic.v4n3a12

\section{RESUMEN}

La endocarditis infecciosa (EI) derecha causa 5-10\% de los casos de El. Es más frecuente en adictos a drogas vía parenteral, aunque puede ocurrir en pacientes con dispositivos intracardiacos, catéteres venosos o cardiopatías congénitas. Las manifestaciones más comunes son fiebre persistente, bacteriemia y émbolos sépticos pulmonares. La cirugía está recomendada cuando los síntomas son intratables, fracaso del tratamiento médico ó émbolos sépticos recurrentes. Presentamos el caso de paciente masculino de 44 años inmunodeprimido, quien cursó con endocarditis asociada a catéter de hemodiálisis, con vegetación atrial derecha complicada con múltiples émbolos sépticos pulmonares, sometido a cirugía exitosa de extracción de vegetación.

\section{Keywords \\ $\triangleright$ Right infective endocarditis. \\ $\triangleright$ Pulmonary abscesses. \\ $\triangleright$ Pseudomonas Aureginosa}

\section{ABSTRACT}

Right infective endocarditis (IE) causes 5-10\% of IE cases. It is more common in intravenous drug abuser, although it can occur in patients with intracardiac devices, venous catheters, or congenital heart disease. The most common manifestations are persistent fever, bacteremia, and pulmonary septic emboli. Surgery is recommended when symptoms are intractable, failure of medical treatment, or recurrent septic emboli. We present the case of an immunosuppressed 44-year-old male patient, who presented with endocarditis associated with a hemodialysis catheter, with right atrial vegetation complicated by multiple pulmonary septic emboli, who underwent successful vegetation removal surgery.

\section{Presentación de Caso Clínico}

Paciente masculino de 44 años con antecedente de glomerulonefritis rápidamente progresiva, diagnosticada 6 meses previos en tratamiento inmunosupresor con metilprednisolona, ciclofosfamida y plasmaferesis, en tratamiento sustitutivo con hemodiálisis.

Inició 3 semanas previas a su ingreso con fiebre de predominio nocturno de hasta 39 grados, tos con expectoración y disnea de pequeños esfuerzos. En su valoración inicial se observo en la radiografía de tórax múltiples cavitaciones pulmonares con nivel hidroaereo en su interior compatibles con abscesos pulmonares (figura 1, flechas), se realizó una tomografía de tórax observándose las múltiples cavitaciones pulmonares de forma bilateral (figura 2, flechas), fue referido a nuestro hospital por sospecha de endocarditis infecciosa (El) asociada a catéter de hemodiálisis.

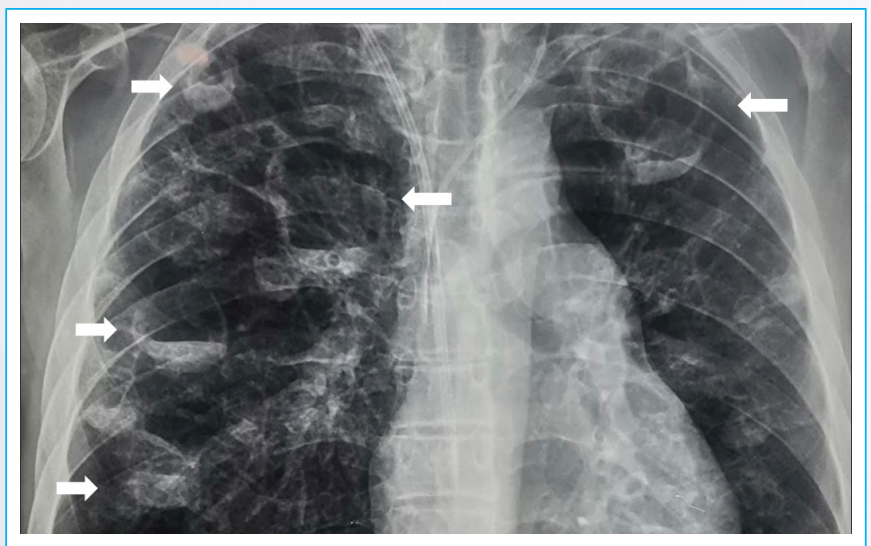

Figura 1. Radiografía de tórax con múltiples cavitaciones pulmonares con nivel hidroaeéreo en su interior compatibles con abscesos pulmonares (flechas). 


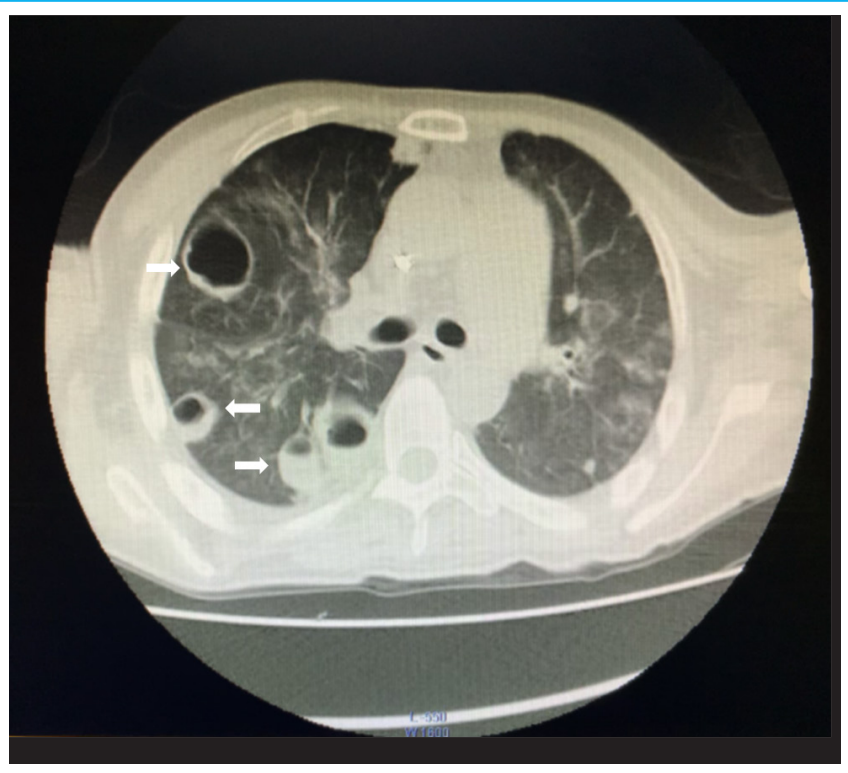

Figura 2. Tomografía de tórax observándose las múltiples cavitaciones pulmonares de forma bilateral (flechas).

A la exploración física con FC 102 lpm, TA 98/60mmHg, FR 18, saturación 97\% al aire ambiente, temperatura de 38.8 grados centígrados, disnea de pequeños esfuerzos, ruidos cardiacos rítmicos, con soplo sistólico en foco tricuspídeo.

El ecocardiograma transtorácico (figuras 3, 4 y video 1) y transesofágico (video 2) mostraron una vegetación gigante localizada en aurícula derecha, que protruye hacia el ventrículo derecho adherida al catéter de diálisis. Los hemocultivos reportaron pseudomonas Aeruginosa, por lo cual se inició antibioticoterapia especifica.

El paciente fue sometido a cirugía para extracción de la gran vegetación, donde se corroboró que la válvula tricúspide no presentaba afectación (figura 5), el paciente cursó con buena evolución.

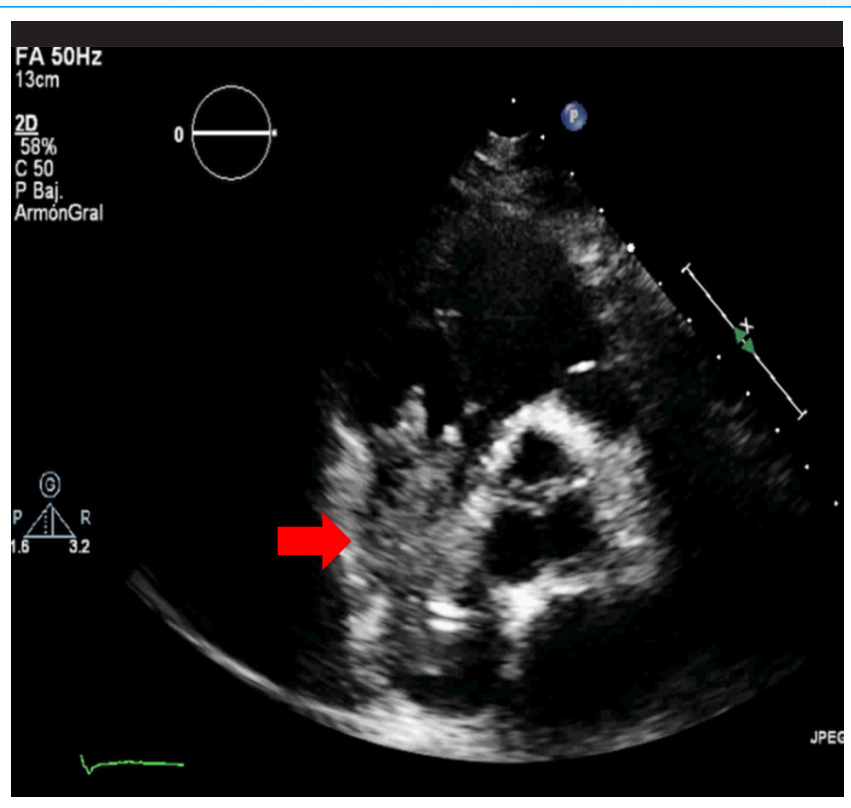

Figura 3. El ecocardiograma transtorácico (eje corto de grandes vasos) mostraba una vegetación gigante localizada en aurícula derecha, que protruía hacia el ventrículo derecho adherida al catéter de diálisis.

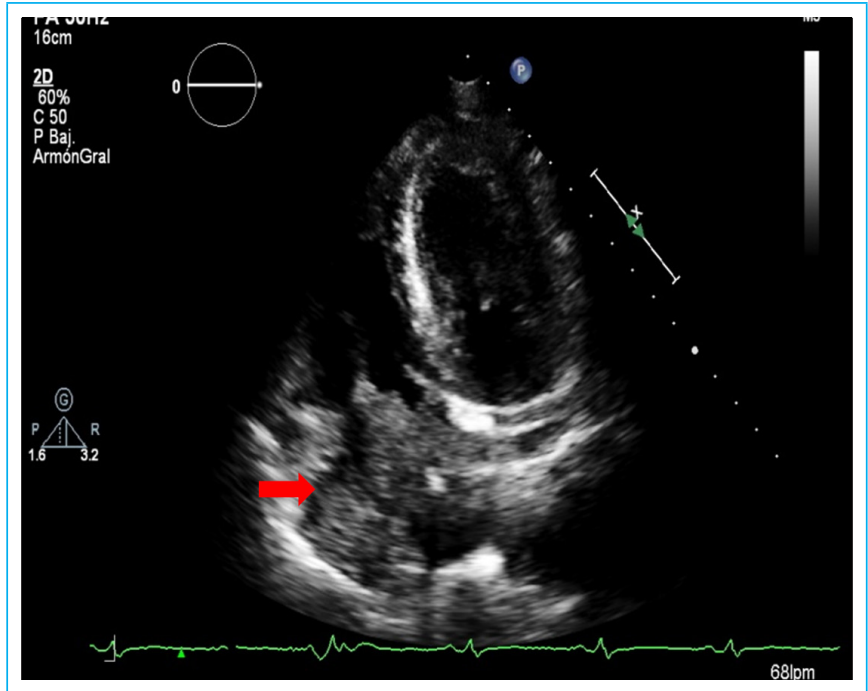

Figura 4. El ecocardiograma transtorácico (apical de 4 cámaras) mostraba una vegetación gigante localizada en aurícula derecha, que protruía hacia el ventrículo derecho adherida al catéter de diálisis.

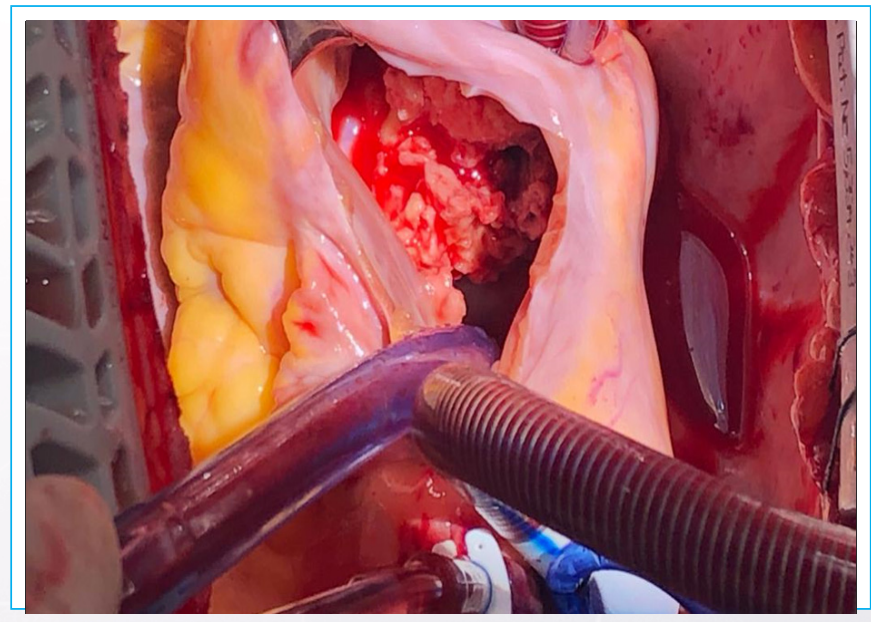

Figura 5. Imagen intraoperatoria que mostraba la extracción de una gran vegetación, donde se corroboró que la válvula tricúspide no presentaba afectación.

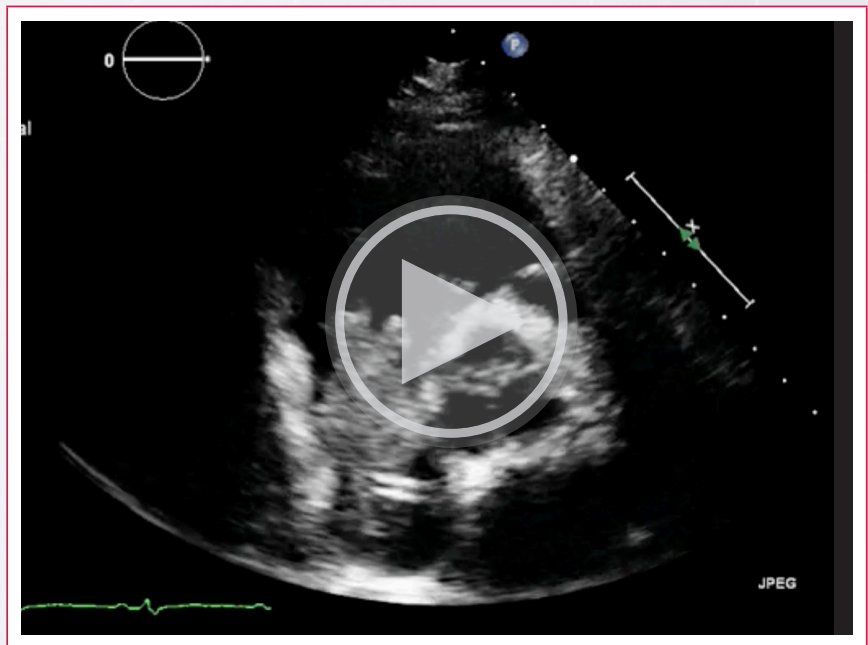

Vídeo 1. El ecocardiograma transtorácico (eje corto de grandes vasos) mostraba una vegetación gigante localizada en aurícula derecha, que protruía hacia el ventrículo derecho adherida al catéter de diálisis. 


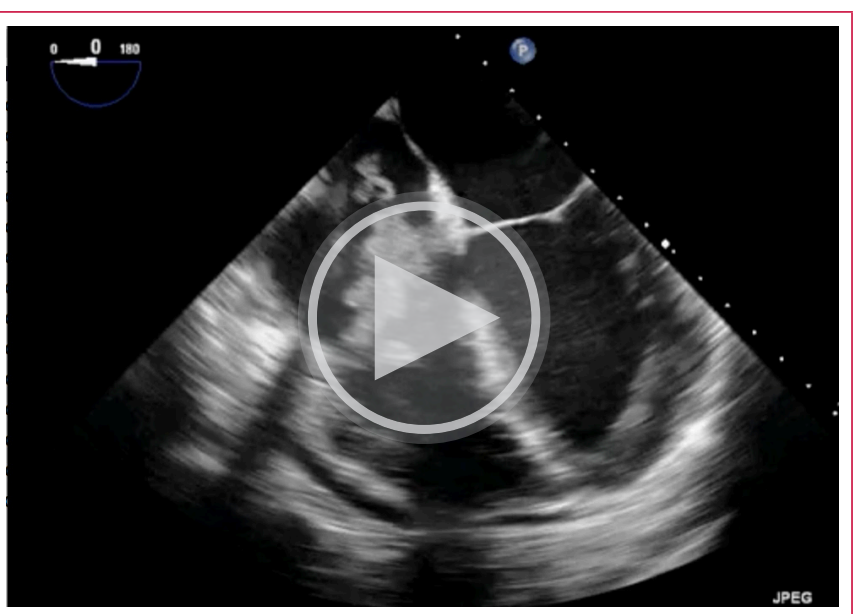

Vídeo 2. El ecocardiograma transesofágica (apical de 4 cámaras) mostraba una vegetación gigante localizada en aurícula derecha, que protruía hacia el ventrículo derecho adherida al catéter de diálisis.

\section{Discusión}

La endocarditis infecciosa (El) derecha causa un 5-10\% de los casos de El. Aunque puede ocurrir en pacientes con marcapasos, desfibrilador implantable, catéter venoso central o cardiopatía congénita, esta situación se observa con más frecuencia en adictos a drogas por vía parenteral (ADVP) ${ }^{(1}$

Las manifestaciones más comunes de la El derecha son fiebre persistente, bacteriemia y múltiples émbolos sépticos pulmonares, que pueden manifestarse en forma de dolor torácico, tos o hemoptisis ${ }^{(2)}$ La ecocardiografía transtorácica suele permitir la evaluación de la enfermedad tricuspídea debido a su localización anterior y las frecuentes vegetaciones grandes. La ETE es más sensible para la detección de vegetaciones pulmonares y afección izquierda asociada. (3-4) Las vegetaciones de longitud $>20 \mathrm{~mm}$ y la etiología fúngica son los principales predictores de muerte en El derecha(2).

La elección de la terapia antimicrobiana empírica depende del microorganismo sospechado, el tipo de droga (en caso de ser ADVP) y la localización de la infección. En cualquier caso, S. aureus tiene que estar cubierto. Una vez que se han aislado los microorganismos causales, es necesario ajustar el tratamiento(2).

Se debe considerar el tratamiento quirúrgico en las siguientes situaciones:

- Microorganismos difíciles de eliminar (p. ej., hongos persistentes) o bacteriemia durante más de 7 días (p. ej., Staphylococcus aureus, Pseudomonas aeruginosa) a pesar de una terapia antibiótica adecuada.

- Vegetaciones > 20 mm en válvula tricúspide persistentes después de émbolos pulmonares recurrentes con ó sin insuficiencia cardiaca (IC) derecha concomitante.

- IC derecha secundaria a insuficiencia tricuspídea grave con mala respuesta al tratamiento diurético ${ }^{(2,5,6)}$.

\section{Conclusión}

La endocarditis infecciosa derecha es una entidad poco frecuente que ocurre principalmente en pacientes adictos de drogas por vía parenteral (ADVP) y en portadores de dispositivos intracardíacos (DIC). En este caso exponemos en paciente portador de catéter de hemodiálisis como factor predisponente así como inmunosupresión por fármacos para el tratamiento de glomerulonefritis rápidamente progresiva. Quien curso con varios indicadores de mal pronóstico como fueron: vegetaciones $>20 \mathrm{~mm}$, presencia de embolismo pulmonar e infección por Pseudomonas Aureginosa, por lo cual requirió una intervención quirúrgica urgente tal como se recomienda en las guías de manejo de El, lo cual le permitió tener una recuperación satisfactoria.

\section{Ideas para recordar}

- La El derecha si bien presenta una menor mortalidad que la El izquierda, presenta una alta morbilidad.

- Se presenta con mayor frecuencia en ADVP y portadores de DIC.

- Las manifestaciones más comunes de la El derecha son fiebre persistente, bacteriemia y múltiples émbolos sépticos pulmonares.

- La ecocardiografía tiene un gran valor en el diagnóstico de estos pacientes.

- La cirugía solo está recomendada cuando los síntomas son intratables, fracaso del tratamiento médico, émbolos sépticos recurrentes a los pulmones o émbolos paradójicos.

\section{Bibliografía}

1. Frontera JA, Gradon JD. Right-side endocarditis in injection drug users: review of proposed mechanisms of pathogenesis. Clin Infect Dis. 2000;30:374-9.

2. 2015 ESC Guidelines for the management of infective endocarditis: The Task Force for the Management of Infective Endocarditis of the European Society of Cardiology. European Heart Journal (2015) 36, 3075-3123.

3. San Roman JA, Vilacosta I, Lopez J, Revilla A, Arnold R, Sevilla T, Rollan MJ. Role of transthoracic and transesophageal echocardiography in right-sided endocarditis: one echocardiographic modality does not fit all. J Am Soc. Echocardiogr. 2012;25:807-14.

4. San Roman JA, Vilacosta I, Zamorano JL, Almeria C, Sanchez-Harguindey L. Transesophageal echocardiography in right-sided endocarditis. J Am Coll Cardiol. 1993;21:1226-30.

5. Gaca JG, Sheng S, Daneshmand M, Rankin JS, Williams ML, O'Brien SM, Gammie JS. Current outcomes for tricuspid valve infective endocarditis surgery in North America. Ann Thorac Surg. 2013;96:1374-81.

6. Akinosoglou K, Apostolakis E, Koutsogiannis N, Leivaditis V, Gogos CA. Rightsided infective endocarditis: surgical management. Eur J Cardiothorac Surg. 2012:42:470-9. 